\title{
EOS Modeling for Libyan Oil Field Using Multiple Wells Fluid PVT Analysis
}

\author{
Abdulhadi Elsounousi Khalifa ${ }^{1 *}$, Anes Tarek Elfituri ${ }^{2}$, Abdalkados Attia Alzawi ${ }^{1}$ \\ ${ }^{1}$ Department of Petroleum Engineering, College of EngineeringTechnolgy,Janzour,Tripoli Libya \\ ${ }^{2}$ Institute of Subsurface Energy System, Clausthal University of Technology, Germany
}

*Corresponding Author: Abdulhadi Elsounousi Khalifa, Department of Petroleum Engineering, College of Engineering Technology, Janzour, Tripoli Libya

\begin{abstract}
Equations of State (EOS) tuning models are being extensively used to model fluid phase behaviour and volumetric properties of crude oil and gas reservoirs. This technique provides the improvement of an enhanced fluid property estimation over conventional black oil models. Once the petroleum fluid system has been probably characterized, its reservoir fluid properties behaviour under a variety of circumstances can simply be evaluated.
\end{abstract}

The objective of this work is to use EOS phase behaviour PVTi Eclipse software to tune experimental PVT data of numerous hydrocarbon fluid samples from onshore Libyan oil field. This work presents the fluid characterization routines, simulations and regression competencies of the PVTi Eclipse software which was used for the estimation of EOS parameters needed to tune laboratory data. The multi-sample characterization technique is used to reach at characterized crude oil sample for the whole reservoir.

Five hydrocarbon samples from onshore Libyan oil field was validated to select the representative samples then characterized using the different (EOS) to reach at one EOS model that precisely describes the reservoir fluids behaviour of hydrocarbon produced from the considered wells in the reservoir.

The hydrocarbon samples are first evaluated for consistency to make sure that samples are representative for hydrocarbon produced. The predictive competency, strength and weakness of these models were consequently compared and analyzed. The matching of fluid properties results with experimental results were done systematically by tuning procedure for the EOS. A consistent C7+ pseudo-component split using the Whitson splitting technique is used for all oil samples to reach at a reliable model for crude oil for the full reservoir. Results exhibited a generally excellent match of PVT properties estimated using the EOS Peng-Robinson three parameters (PR3) model with experimental measurements for this onshore Libyan oil field also absolute average error $(A A E)$ is used throughout the study to quantify comparisons between experimental measurements and calculated data. The EOS model have been developed successfully to determine physical properties and to predict the fluid behaviour of this reservoir which can be used in reservoir simulation studies to enhance hydrocarbon recovery.

Keywords: Fluid properties, Compositional gradient, EOS model.

\section{INTRODUCTION}

Hydrocarbon systems originated in crude oil reservoirs are recognized to exhibit multiphase behavior over large ranges of pressures and temperatures. The most significant phases that occur in hydrocarbon reservoirs are a liquid phase, such as crude oils or condensates, and a gas phase, such as natural gases.

The conditions under which these phases happen are a matter of considerable practical importance. The experimental or the analytical estimations of these situations are suitably exhibited in variety types of diagrams, usually named phase diagrams.[1]

Most of PVT estimations carried out for hydrocarbon mixtures are based on a cubic equation of state. That kind of equations dates back to the famous van der Waals equation more than 100 years ago. The cubic equation of state most widely used in today's petroleum industry are very similar to the van der Waals equation but it took the petroleum industry almost a century to accept this type of equation as a valuable engineering tool. The first cubic equation of state to get widespread use was that proposed in 
1949 by Redlich and Kwong. The equation was further developed in the 1970s by Soave and Peng and Robinson. Peneloux et al. introduced a definition of volume-shift with a view to enhancing the liquid density predictions of the two previous equations. The increased use of cubic equation of state seen over the past 30 years is largely due to the availability of inexpensive computer power which has allowed millions of multicomponent phase equilibrium and physical property calculations to be performed within seconds using a state equation as the thermodynamic basis.[2]

\section{EOS MODEL DEVELOPMENT}

Petroleum industry is widely using Cubic Equation of state (EOS) models which they are mostly used for:

- Reservoir modeling with a compositional simulator.

- Generating black-oil or modified black-oil PVT formulations for reservoir simulators.

- Production and process engineering calculations.

In general, the predictive capabilities of the cubic EOS are often questionable for multi-component petroleum mixtures, without proper tuning. In other words, models of phase behavior based on these equations can predict highly erroneous outcomes, particularly for near critical fluids. Currently, the industry approach to enhancing an EOS model's predictive capabilities is to tuning it against experimental data produced in the PVT laboratory at different pressure and temperature conditions. While the industry has no consensus on a single standard tuning technique, there are some parallels between the various approaches. The basic concept for tuning an EOS is to change certain unknown values of the EOS input parameters to minimize the discrepancy between the expected values and the laboratory value.[3]

It is important to establish a specific EOS for a field / basin because in-situ reservoir fluids can differ spatially, change composition during extraction and gas injection, and fluid mixing in the production system - in reservoirs, wells, and topside facilities..[4]

The Soave-Redlich-Kwong (SRK) and Peng-Robinson (PR) EOS are among the most widely used cubic EOS's in the petroleum industry, among other available EOS's. Both equations have the same precision for predictions of vapor-liquid equilibrium and sufficient volumetric predictions for phases by applying volume translation. The PR EOS provides a slightly improved action prediction at the critical point and an improved estimate of liquid densities than SRK EOS.[5]

\subsection{Laboratory Characterization}

The available date in this study is a set of a routine PVT laboratory tests for five bottom-hole fluid samples for Libyan oil field that operated by Libyan Oil Company. Differential liberation (DL), constant composition expansion (CCE), and separator tests (SEPS) data are available for all wells with whole analysis of extracted vapor during DL and separator experiments.

All crude oil samples are sweet black oil as the percentage of hydrogen sulfide is negligible and the mole fraction of $\mathrm{C} 7+$ for all samples is greater than $30 \%$. All samples are collected at well flowing condition. Samples information is shown in Table 1.

Table1. Samples information

\begin{tabular}{|c|c|c|c|c|}
\hline Well & Laboratory & Well Condition & Type of sample & Depth of sample \\
\hline F1 & ExPro Lab & Flowing & Bottom Hole & $6000 \mathrm{ft}$ \\
\hline F2 & Schlumberger & Flowing & Bottom Hole & $5950 \mathrm{ft}$ \\
\hline F3 & Schlumberger & Flowing & Bottom Hole & $5872 \mathrm{ft}$ \\
\hline F4 & Schlumberger & Flowing & Bottom Hole & $5903 \mathrm{ft}$ \\
\hline F5 & Schlumberger & Flowing & Bottom Hole & $5940 \mathrm{ft}$ \\
\hline
\end{tabular}

The bubble point pressure, flash and viscosity test for all wells are shown in Table 2

Table2. Saturation pressure, flash and viscosity test

\begin{tabular}{|c|c|c|c|c|c|c|c|c|}
\hline Well & $\begin{array}{c}\text { Sampling } \\
\text { Depth }\end{array}$ & $\mathrm{Pb}$ & $\beta \mathrm{O}$ & GOR & API & $\mu$ oi & $\mu \mathrm{ob}$ & $\mu$ od \\
\hline & $\mathrm{ft}$ & $\mathrm{psia}$ & $\mathrm{bbl/STB}$ & Scf/STB & degree & $\mathrm{cp}$ & $\mathrm{cp}$ & $\mathrm{cp}$ \\
\hline F1 & 6000 & 1927 & 1.415 & 633 & 42.74 & 0.39 & 0.36 & 1.70 \\
\hline F2 & 5950 & 1895 & 1.369 & 586 & 42.4 & 0.43 & 0.39 & 1.77 \\
\hline F3 & 5872 & 1840 & 1.413 & 650 & 41.6 & 0.46 & 0.36 & 1.60 \\
\hline
\end{tabular}




\begin{tabular}{|l|c|c|c|c|c|c|c|c|}
\hline F4 & 5903 & 1880 & 1.421 & 668 & 41.8 & 0.46 & 0.38 & 1.69 \\
\hline F5 & 5940 & 1906 & 1.459 & 719 & 42 & 0.46 & 0.37 & 1.41 \\
\hline
\end{tabular}

\subsection{Data Validation}

The data was measured by accumulating the main fluid parameters such as fluid properties and composition. Then plotting the reservoir fluid properties versus depth to confirm a uniform vertical compositional gradient. The bubble point pressures, the percentage of both methane and heptane plus and API are used for such plots. Comparing of fluid composition with depth for all wells are shown in Table 3.

The inspection of $\mathrm{C} 1$ fraction vs. depth have a linear trend without any different trend for all samples, and also shows that increasing in $\mathrm{C} 7+$ mole fraction with depth, which is to be expected, for all samples as shown in Fig. 1.

The inspection of bubble point pressure and API vs. depth, presented in all samples have no different a trend for all value as shown in Fig.2. The plots for Fig. $2 \& 3$ indicated that the fluid from all wells are representative samples comparing with the whole samples. This conclusion led to constructing the fluid EOS model for the reservoir based on the fluids coming from whole wells.

Table3. Fluid composition with depth

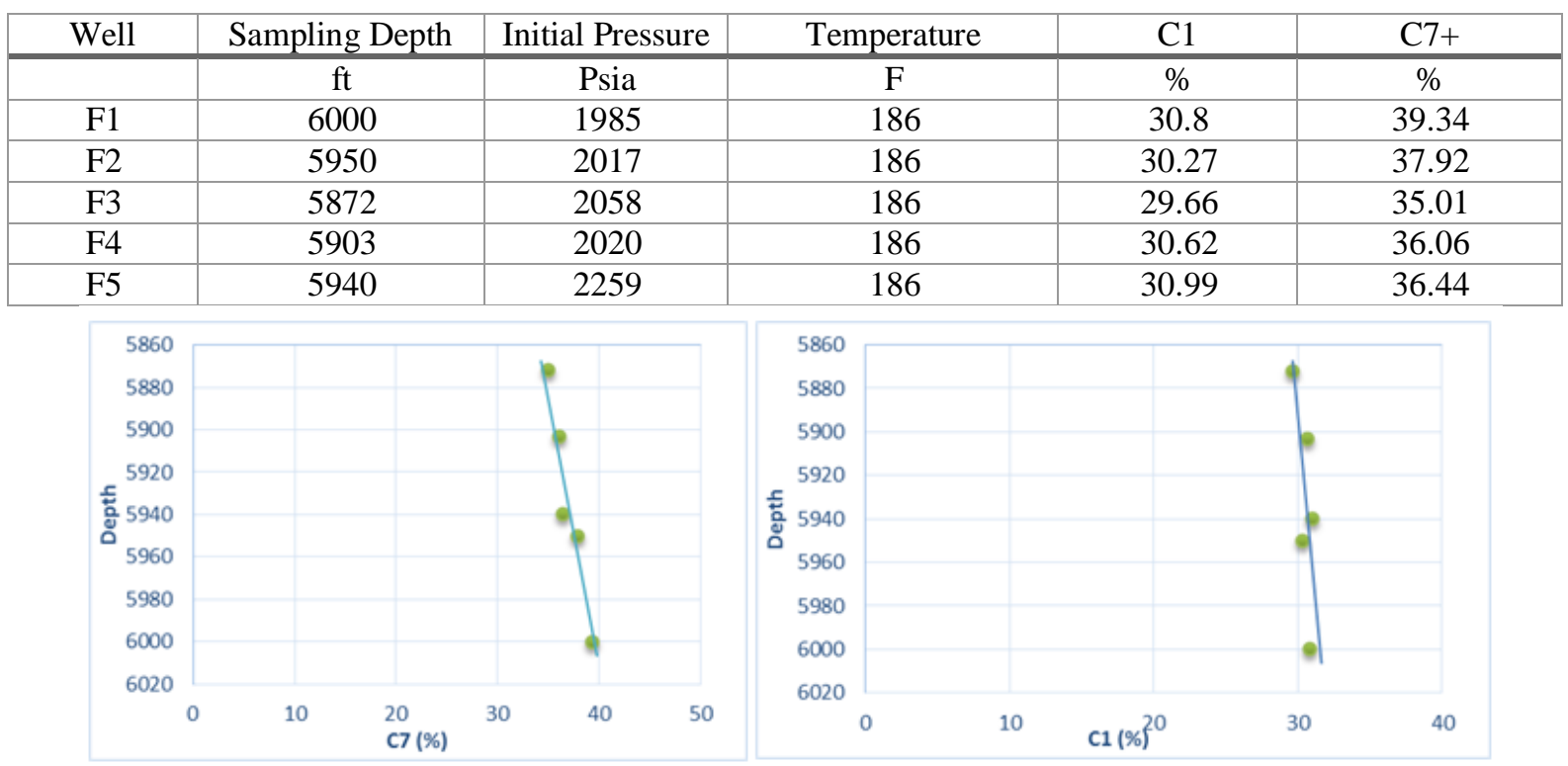

Fig1. $C 1 \& C 7+$ vs. depth

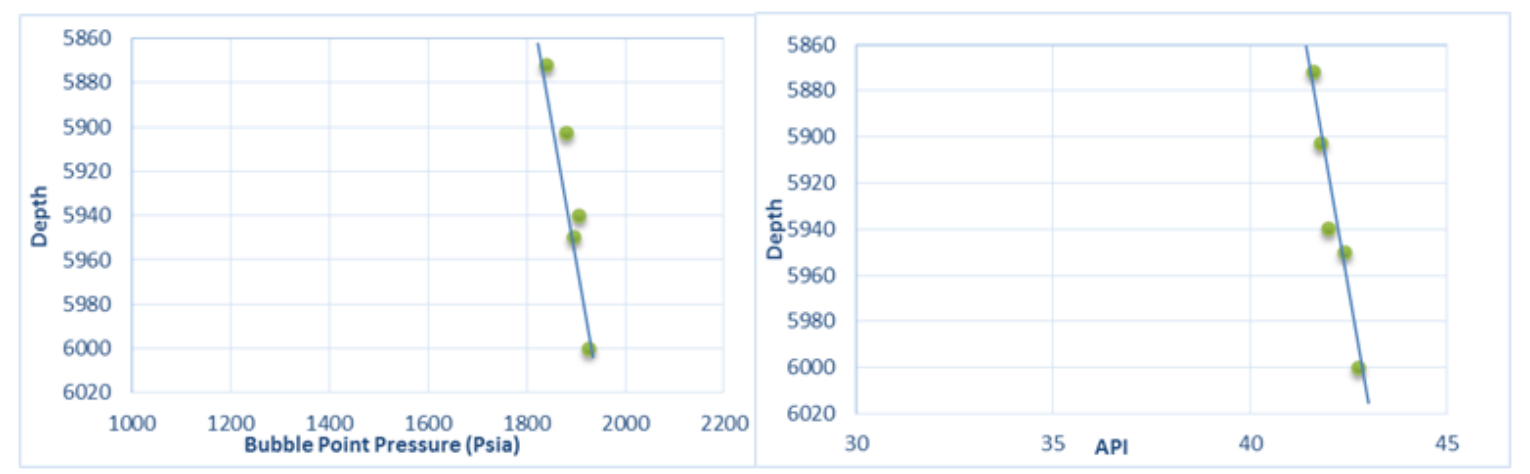

Fig2. Pb\&API vs. depth

\section{DisCUSSION OF RESULTS}

The Schlumberger phase behavior (PVTi) package, along with the Soave-Redlich-Kwong (SRK) and Peng Robinson $2 \& 3$ parameters equation of state were used. PVTi contains facilities to allow you to import experimental data, fit the data to an EOS, then finally produce the PVT tables for reservoir simulation studies. Fig.3 shows the main window of PVTi which contains all the tools necessary for EOS model fitting. 


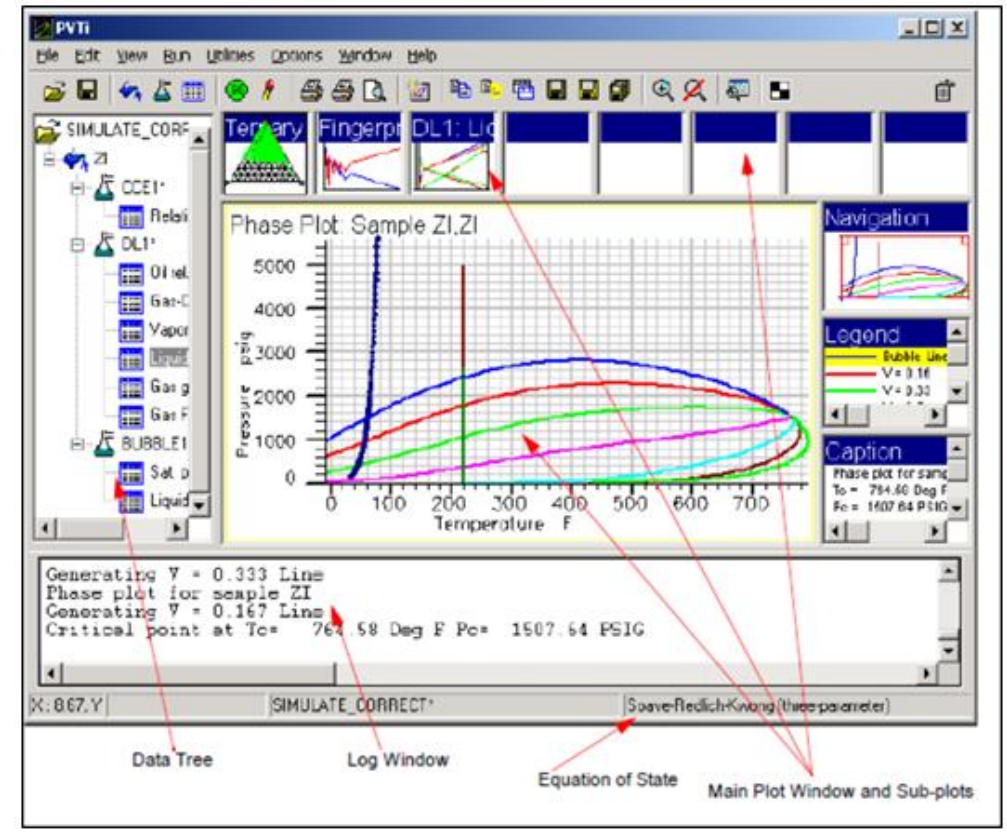

Fig3. PVTi package[6]

The first step in this work was to validated and analyzed the samples for accuracy to ensure that they are representative of oil extractedfrom PVT data through comparison technique using sample conditions, fluid composition and fluid properties to select the candidates sample from five PVT samples form Libyan oil field. Then using the multi-sample characterization method to reach at characterized sample for crude oil for complete reservoir. The tuning method for the EOS was done consistently by matching the fluid properties results with experimental results. In addition, a consistent $\mathrm{C} 7+$ pseudo-component split using the Whitson splitting technique is used for all samples to reach at a consistent model for crude oil for the entire reservoir.

A phase behavior modeling was administered using the PVTi modules from commercial (Schlumberger) simulators for well F-1 shows at Fig.4 below, which confirming that the sample is black oil for this well.

Peng-Robinson (3-Parmameters) and Viscosity Correlation (Lohrenz-Bray-Clark) are selected to be used in experimental work using the PVTi Simulator for well-F1.

Results from the PVT experiments are imported into PVTi software for validation in order to ascertain a good match between the simulated and experimental data.Then tuning the main parameters of EOS such as critical pressure and temperature, $\Omega \mathrm{A}$ and $\Omega \mathrm{B}$, acentric factor and binary interaction between components to match experiments' PVT data with the simulation results.

The results shows good matching for the routine PVT data for well-F1 after tuning the PR 3 parameters.

Table 4. Shows predicted saturation pressure without tuning and after tuning for different EOS using PVTi software, for well-F1 along with the absolute relative errors.

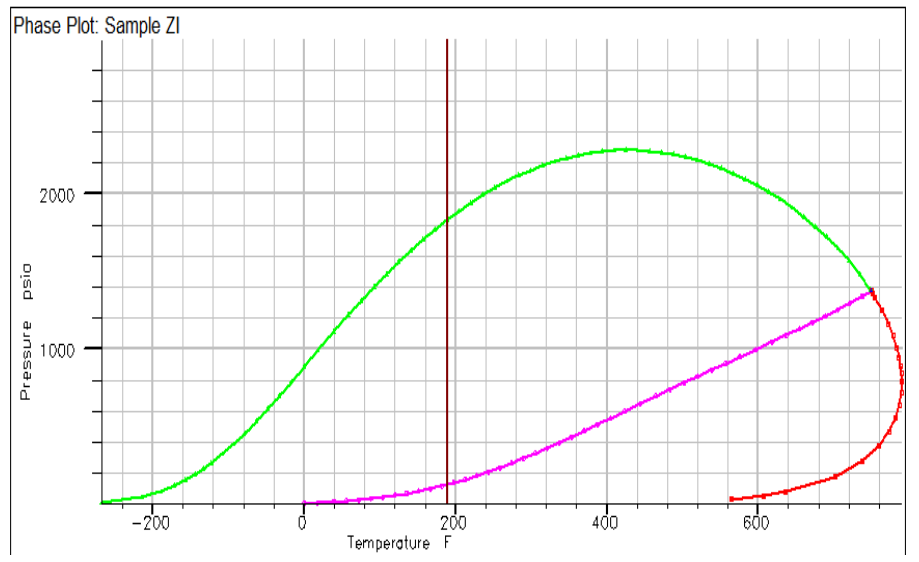

Fig4. Phase diagram for well $F-1$ 
Table4. Predicted $\mathrm{Pb}$ before and after tuning for different EOS

\begin{tabular}{|c|c|c|}
\hline \multicolumn{2}{|c|}{ Experimental saturation pressure, psia } & ARE\% \\
\hline Method & Calculated saturation pressure, psia & 0.62 \\
\hline Without tuning PR3 & 1915 & 1.4 \\
\hline Without tuning SRK3 & 1900 & 1.92 \\
\hline Without tuning PR2 & 1890 & 0.08 \\
\hline With tuning PR3 & 1925.41 & 0.44 \\
\hline With tuning SRK3 & 1918.5 & 1.12 \\
\hline With tuning PR2 & 1905.3 & \\
\hline
\end{tabular}

The saturation pressure has been obtained using PR3 is 1925.41 psia which has an Absolute Relative Error $(\mathrm{ARE} \%)=0.08 \%$ compared with measured bubble point pressure (1927 psia). Figures from (5.a) to (5.c) show the results of matching the differential liberation test for well-F1

It is clear that there is a significant improvement in the simulated EOS values after regression, which indicates the good matching steps using Peng Robinson three parameters equation also significance of adjusting the equation parameters.

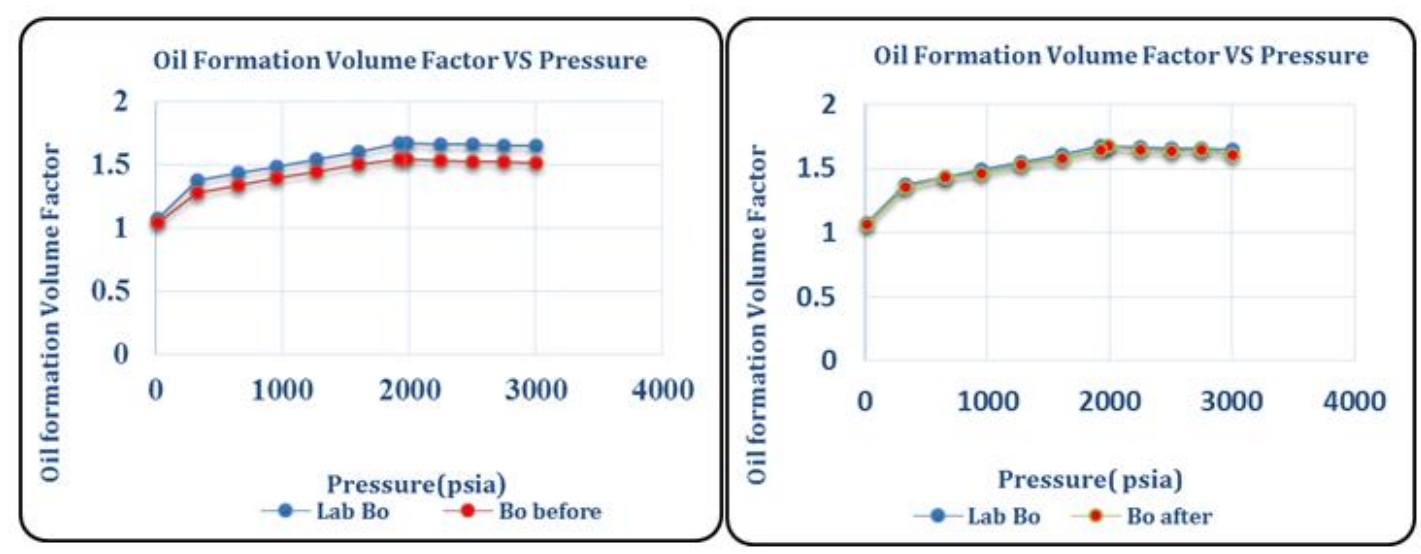

Fig5a. Oil formation volume factor using PR3 before and after tuning

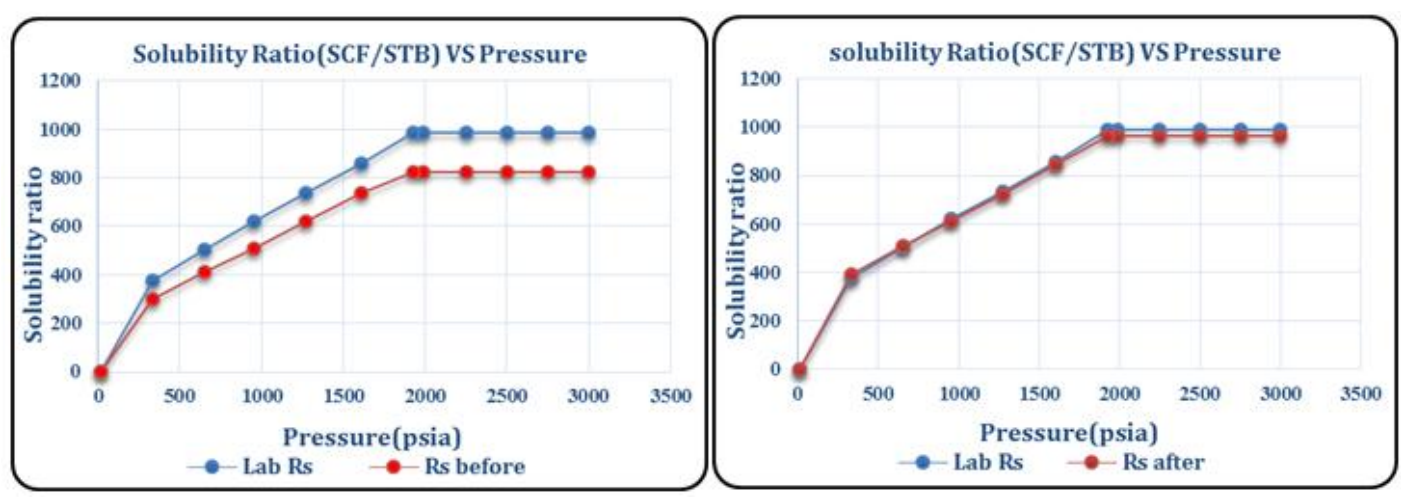

Fig5b. Solubility ratio using PR3 before and after tuning

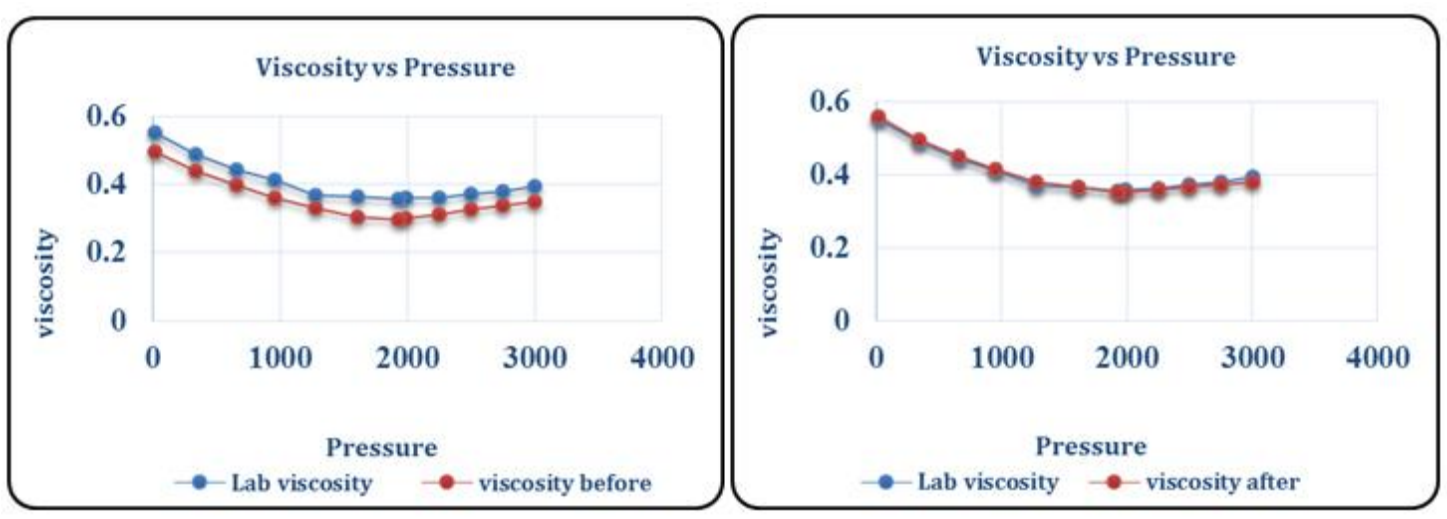

Fig5c. Viscosity using PR3 before and after tuning 
The results for calculated and experimental DL data are presented in Table 5.1 to 5.4 along with the relative errors for well-F1 using PR3

Table5.1. Measured and Predicted Oil Formation Volume factor results for well-F1

\begin{tabular}{|c|c|c|c|c|}
\hline $\begin{array}{c}\text { Pressure } \\
(\mathrm{psia})\end{array}$ & Lab(measured) $\beta_{\mathrm{o}}$ bbl/STB & Predicted Before Tuning & Predicted After Tuning & ARE\% \\
\hline 3000 & 1.647 & 1.5134 & 1.6212 & 1.566 \\
\hline 2750 & 1.652 & 1.5198 & 1.6277 & 1.471 \\
\hline 2500 & 1.659 & 1.5266 & 1.6346 & 1.471 \\
\hline 2250 & 1.664 & 1.5338 & 1.6419 & 1.328 \\
\hline 1985 & 1.672 & 1.5419 & 1.65 & 1.316 \\
\hline 1927 & 1.674 & 1.5437 & 1.665 & 0.537 \\
\hline 1607 & 1.604 & 1.5047 & 1.5932 & 0.673 \\
\hline 1273 & 1.547 & 1.4458 & 1.5341 & 0.834 \\
\hline 953 & 1.489 & 1.3917 & 1.4787 & 0.692 \\
\hline 655 & 1.435 & 1.3416 & 1.4265 & 0.592 \\
\hline 335 & 1.377 & 1.2814 & 1.3616 & 1.118 \\
\hline 15 & 1.075 & 1.0454 & 1.0408 & 3.181 \\
\hline
\end{tabular}

Table5.2. Measured and Predicted Gas Oil Ratio results for well-F1

\begin{tabular}{|c|c|c|c|c|}
\hline $\begin{array}{c}\text { Pressure } \\
\text { (psia) }\end{array}$ & $\begin{array}{c}\text { Lab(measured) } \\
\text { GOR Scf/STB }\end{array}$ & Predicted Before Tuning & Predicted After Tuning & ARE\% \\
\hline 3000 & 988 & 823 & 988 & 0.00 \\
\hline 2750 & 988 & 823 & 988 & 0.00 \\
\hline 2500 & 988 & 823 & 988 & 0.00 \\
\hline 2250 & 988 & 823 & 988 & 0.00 \\
\hline 1985 & 988 & 823 & 988 & 0.00 \\
\hline 1927 & 988 & 823 & 988 & 0.00 \\
\hline 1607 & 858 & 738 & 845 & 1.52 \\
\hline 1273 & 736 & 619 & 724 & 1.63 \\
\hline 953 & 621 & 511 & 613 & 1.29 \\
\hline 655 & 503 & 413 & 511 & 1.59 \\
\hline 335 & 378 & 302 & 393 & 3.97 \\
\hline
\end{tabular}

Table5.3. Measured and Predicted Oil Density results for well-F1

\begin{tabular}{|c|c|c|c|c|}
\hline Pressure(psia) & Lab(measured) $\rho$ Ib/cu ft & $\begin{array}{c}\text { Predicted Before } \\
\text { Tuning }\end{array}$ & $\begin{array}{c}\text { Predicted After } \\
\text { Tuning }\end{array}$ & ARE\% \\
\hline 3000 & 42.02 & 42.37 & 42.22 & 0.476 \\
\hline 2750 & 41.98 & 42.20 & 42.05 & 0.167 \\
\hline 2500 & 41.81 & 42.01 & 41.88 & 0.167 \\
\hline 2250 & 41.68 & 41.81 & 41.69 & 0.024 \\
\hline 1985 & 41.51 & 41.59 & 41.48 & 0.072 \\
\hline 1927 & 41.48 & 41.54 & 41.45 & 0.07 \\
\hline 1607 & 42.48 & 42.05 & 42.16 & 0.753 \\
\hline 1273 & 43.47 & 42.93 & 42.95 & 1.196 \\
\hline 953 & 44.43 & 43.80 & 43.74 & 1.553 \\
\hline 655 & 45.44 & 44.64 & 44.52 & 2.025 \\
\hline 335 & 46.53 & 45.68 & 45.5 & 2.214 \\
\hline
\end{tabular}

Table5.4. Measured and Predicted Oil Viscosity results for well-F1

\begin{tabular}{|c|c|c|c|c|}
\hline $\begin{array}{c}\text { Pressure } \\
\text { (psia) }\end{array}$ & Lab(measured) $\mu$ o & Predicted Before Tuning & Predicted After Tuning & ARE\% \\
\hline 3000 & 0.393 & 0.348 & 0.391 & 0.50 \\
\hline 2750 & 0.381 & 0.337 & 0.373 & 2.100 \\
\hline 2500 & 0.372 & 0.326 & 0.367 & 0.344 \\
\hline 2250 & 0.362 & 0.314 & 0.36 & 0.552 \\
\hline 1985 & 0.359 & 0.302 & 0.353 & 1.671 \\
\hline 1927 & 0.357 & 0.299 & 0.355 & 0.56 \\
\hline 1750 & 0.365 & 0.304 & 0.365 & 3.000 \\
\hline 1500 & 0.369 & 0.331 & 0.381 & 3.252 \\
\hline
\end{tabular}

$\begin{array}{lr}\text { International Journal of Petroleum and Petrochemical Engineering } & \text { Page } 6\end{array}$ 


\begin{tabular}{|c|c|c|c|c|}
\hline & & & \\
\hline 1250 & 0.412 & 0.362 & 0.416 & 0.971 \\
\hline 1000 & 0.444 & 0.398 & 0.451 & 1.577 \\
\hline 750 & 0.489 & 0.441 & 0.495 & 1.227 \\
\hline 500 & 0.553 & 0.496 & 0.561 & 1.447 \\
\hline 250 & 0.669 & 0.578 & 0.688 & 2.840 \\
\hline 15 & 1.70 & 0.861 & 1.688 & 0.705 \\
\hline
\end{tabular}

The Summary of comparing measured and predicted reservoir properties results are presented in Table 6 along with the relative errors for well-F1 using PR3.

Table6. Summary of Measured and Predicted reservoir properties for well-F1

\begin{tabular}{|c|c|c|c|c|}
\hline PVT well-F1 & EOS & Measured & Predicted & ARE\% \\
\hline Pb (psia) & PR-3 & 1927 & 1925.41 & 0.08 \\
\hline Bob (bbl/STB) & PR-3 & 1.674 & 1.665 & 0.537 \\
\hline Rs (scf/STB) & PR-3 & 988 & 988 & 0.00 \\
\hline$\rho o b(\mathrm{Ib} / \mathrm{cu} \mathrm{ft})$ & PR-3 & 41.48 & 41.45 & 0.07 \\
\hline$\mu \mathrm{ob}(\mathrm{cp})$ & PR-3 & 0.357 & 0.355 & 0.56 \\
\hline$\mu \mathrm{od}(\mathrm{cp})$ & PR-3 & 1.70 & 1.688 & 0.705 \\
\hline
\end{tabular}

The comparing of PVT modeling results between SRK \& PR two and three parameters equations of state at saturation pressure of five wells are shown in Table 7.

Table7. Measured and Predicted Saturation Pressure results

\begin{tabular}{|c|c|c|c|c|}
\hline Well & EOS & Measured Pb & Predicted Pb & ARE\% \\
\hline F1 & PR-3 & 1927 & 1925 & 0.08 \\
\hline F2 & PR-2 & 1841 & 1831 & 0.54 \\
\hline F3 & SRK-2 & 1859 & 1848 & 0.59 \\
\hline F4 & SRK-3 & 1900 & 1893 & 0.368 \\
\hline F5 & PR-3 & 1906 & 1902 & 0.209 \\
\hline
\end{tabular}

The range of average absolute error for the bubble point pressure is $0.08 \%$ to 0.59 . An excellent prediction already exists for the simulated bubble point pressure with errors of less than $0.5 \%$ for most of wells, only wells F2 and F3 have highly error compared to the other wells using Soave-RedlichKwong (SRK) and Peng Robinson 2 parameters equation of state.

Summary of the comparison between experimental and simulated differential liberation test results are shown in Table 8. The absolute relative error for the oil formation volume factor at bubble point pressure is in range $0.53 \%$ to $1.02 \%$, absolute relative error for the gas oil ratio at bubble point pressure is in range $0.0 \%$ to $1.14 \%$ and absolute relative error for the oil density at bubble point pressure is in range $0.07 \%$ to $0.91 \%$, these results indicated a very good prediction already exists for the simulated properties with errors of less than $1 \%$ using PR3\&SKR3.

Table8. Experimental and simulated differential liberation results

\begin{tabular}{|c|c|c|c|c|c|c|c|c|c|c|}
\hline Well & EOS & $\begin{array}{c}\text { Measu } \\
\text { red }\end{array}$ & Predicted & $\begin{array}{c}\text { ARE } \\
\%\end{array}$ & Measured & Predicted & $\begin{array}{c}\text { ARE } \\
\%\end{array}$ & Measured & Predicted & $\begin{array}{c}\text { ARE } \\
\%\end{array}$ \\
\hline & & \multicolumn{3}{|c|}{ Bob } & \multicolumn{3}{|c|}{ Rs } & \multicolumn{3}{|c|}{ $\rho$ ob } \\
\hline F1 & PR-3 & 1.674 & 1.665 & 0.537 & 988 & 988 & 0.00 & 41.48 & 41.45 & 0.07 \\
\hline F2 & PR-2 & 1.538 & 1.525 & 0.84 & 792 & 784 & 1.01 & 42.13 & 41.84 & 0.68 \\
\hline F3 & SRK-2 & 1.585 & 1.601 & 1.02 & 876 & 886 & 1.14 & 41.45 & 41.07 & 0.91 \\
\hline F4 & SRK-3 & 1.558 & 1.547 & 0.7 & 830 & 836 & 0.72 & 41.51 & 41.21 & 0.72 \\
\hline F5 & PR-3 & 1.677 & 1.669 & 0.47 & 943 & 942 & 0.10 & 39.82 & 40.0 & 0.45 \\
\hline
\end{tabular}

Summary of the comparison between experimental and simulated viscosity results. The absolute relative error for the oil viscosity at bubble point pressure is in range $0.35 \%$ to $5.5 \%$ and absolute relative error for the dead oil viscosity is in range $0.7 \%$ to $15.2 \%$ these results indicated a good prediction already exists for the simulated oil viscosity using PR3.The results is shown in Table 9.

Table9. Experimental and simulated viscosity results

\begin{tabular}{|c|c|c|c|c|c|c|c|}
\hline Well & EOS & Measured & Predicted & ARE\% & Measured & Predicted & ARE\% \\
\hline \multicolumn{3}{|c|}{} & \multicolumn{3}{|c|}{$\mu$ ob } \\
\hline F1 & PR-3 & 0.357 & 0.355 & 0.56 & 1.70 & 1.688 & 0.705 \\
\hline F2 & PR-2 & 0.39 & 0.41 & 5.12 & 1.77 & 1.50 & 15.2 \\
\hline F3 & SRK-2 & 0.36 & 0.38 & 5.5 & 1.60 & 1.40 & 12.5 \\
\hline
\end{tabular}




\begin{tabular}{|c|c|c|c|c|c|c|c|}
\hline F4 & SRK-3 & 0.38 & 0.39 & 2.63 & 1.69 & 1.6 & 5.32 \\
\hline F5 & PR-3 & 0.37 & 0.367 & 0.81 & 1.41 & 1.39 & 1.41 \\
\hline
\end{tabular}

\section{CONCLUSION}

The study has confirmed the convenienceof the multi-well characterization approach to model the PVT properties of oil reservoirs. It given a unique EOS description that is accurate for all checked samples.Excellent results were obtained from simulation and matching of EOS for the samples from the whole wells using a combination of DL and CCE test data.From the multiple options available to tune the EOS and Splitting \& grouping techniques, the characterization of the $\mathrm{C} 7+$ fraction was sufficient to get a close match with experimental values. Also tuning the main parameters of EOS such as critical pressure and temperature, $\Omega \mathrm{A}$ and $\Omega \mathrm{B}$, acentric factor and binary interaction between components. PR3 is the most flexible and high accuracy equation in this study.

\section{NOMENCLATURE}

- $\beta_{\mathrm{o}}$ oil formation volume factor, bbl/STB

- $\mathrm{B}_{\mathrm{ob}}$

- API oil formation volume factor at bubble point pressure, bbl/STB

- GOR stock-tank oil gravity, $\mathrm{API}^{\mathrm{o}}$

- $\mathrm{P}$ gas oil ratio

- $\mathrm{P}_{\mathrm{b}}$ pressure, psia

- PVT bubble point pressure, psia

- Rs

- SCF pressure-volume-temperature

- $\mathrm{STB}$

- $\mathrm{T}$ solution gas-oil-ratio, SCF/STB

- $\rho_{\mathrm{ob}}$ standard cubic feet stock tank barrel reservoir temperature, ${ }^{\circ} \mathrm{F}$

- $\mu_{\mathrm{o}}$ oil density at bubble point pressure, $\mathrm{Ib} / \mathrm{cu} \mathrm{ft}$

- $\mu_{\mathrm{ob}}$

- $\mu_{\text {od }}$ viscosity of under-saturated oil, $\mathrm{cp}$ viscosity of saturated oil, $\mathrm{cp}$ viscosity of the dead oil as measured at 14.7 psia and reservoir temperature, $\mathrm{cp}$

\section{REFERENCES}

[1] T. Ahmed, Equations of State and PVT Analysis: Applications for Improved Reservoir Modeling: Second Edition. 2016.

[2] Karen Schou Pedersen. Peter L. christensen. Jawad Azeem Shaikh.Phase Behavior of Petroleum Reservoir Fluids Second Edition.( 2015) .

[3] M. T. Ali and A. H. El-Banbi, "EOS tuning - Comparison between several valid approaches and new recommendations," Soc. Pet. Eng. - SPE North Africa Tech. Conf. Exhib. 2015, NATC 2015, no. 1, pp. 1588-1604, 2015, doi: 10.2118/175877-ms.

[4] B. Younus, C. H. Whitson, A. Alavian, M. L. Carlsen, S. Martinsen, and K. Singh, "Field-wide equation of state model development," SPE/AAPG/SEG Unconv. Resour. Technol. Conf. 2019, URTC 2019, pp. 140, 2019, doi: 10.15530/urtec-2019-551.

[5] O. J. Mkinga, J. Kleppe, R. W. Rwechungura, and M. L. Raphael, "EOS Model and Black-Oil PVT Table Generation for a Tanzanian Reservoir," Int. J. Appl. Sci. Technol., vol. 9, no. 2, pp. 79-88, 2019, doi: 10.30845/ijast.v9n2p8.

[6] R. B. J. Brinkgreve and S. Kumarswamy, "Reference Manual Reference Manual," Technology, vol. 1, no. November, 2008, doi: 10.1093/cid/ciq238.

Citation: Abdulhadi Elsounousi Khalifa, et.al, "EOS Modeling for Libyan Oil Field Using Multiple Wells Fluid PVT Analysis", International Journal of Forestry and Horticulture, 6(2), pp. 1-8. DOI: http://dx.doi.org/10.20431/2454-7980.0602001

Copyright: () 2020 Authors, This is an open-access article distributed under the terms of the Creative Commons Attribution License, which permits unrestricted use, distribution, and reproduction in any medium, provided the original author and source are credited. 